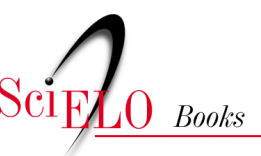

El entramado civilización, educación y evangelización en el territorio

\title{
Conclusiones generales, aporte y preguntas pendientes
}

José Enrique Juncosa Blasco

\section{SciELO Books / SciELO Livros / SciELO Libros}

JUNCOSA BLASCO, J. E. Conclusiones generales, aporte y preguntas pendientes. In: Civilizaciones en disputa: Educación y evangelización en el territorio Shuar [online]. Quito: Universidad Andina Simón Bolívar, Sede Ecuador; Editorial Abya-Yala, 2020, pp. 295-301. Investigación Decolonial series, n. 3. ISBN: 978-9978-10-458-3. http://doi.org/10.7476/9789978105696.0007.

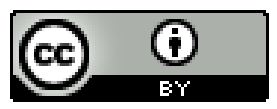

All the contents of this work, except where otherwise noted, is licensed under a Creative Commons Attribution 4.0 International license. Todo o conteúdo deste trabalho, exceto quando houver ressalva, é publicado sob a licença Creative Commons Atribição 4.0.

Todo el contenido de esta obra, excepto donde se indique lo contrario, está bajo licencia de la licencia Creative Commons Reconocimento 4.0. 


\section{CONCLUSIONES GENERALES, APORTE Y PREGUNTAS PENDIENTES}

\section{Conclusiones generales}

La principal conclusión consiste en que aquel saber que ha permitido prevalecer a los shuar en el territorio se articula en torno a la opción por su existencia diferenciada, en tanto diferencia radical. Y esa opción, ha sido alimentada por la espiritualidad de Arutam, núcleo desde el que es posible articular una pedagogía más allá de la educación formal y una epistemología shuar antihegemónicas y decoloniales, vinculadas a la expansión de la vida colectiva en el territorio. Aquello que renace o busca aún renacer ha sido, en el fondo, la espiritualidad de Arutam. Esa espiritualidad es la que resiste los embates y es la que permanece viva a pesar de todo.

En torno a esta primera intuición, que cierra el esquema narrativo de la investigación, es posible derivar a las siguientes conclusiones:

- La presencia salesiana implantó distintas formas de escolaridad, según las modalidades históricas de los internados, como plataforma de posibilidad de su proyecto civilizatorio y evangelizador, valorado este último como aquel que da sentido a la misión. La accionalidad shuar logró apropiarse de la educación porque la escritura fue considerada un elemento clave para defenderse de la colonización. Asimismo, la evangelización fue considerada como una moneda de cambio en función de acceder a la educación.

- Las formas de escolaridad articularon proyectos civilizatorios heterogéneos, siempre en el marco de la modernidad-colonialidad instaurada como única presencia posible, como el de cocivilización con los colonos, que buscó modelar a los shuar como mestizos y campesinos. Luego, advino el proyecto civi- 
lizatorio que reconoció la diferencia shuar como parte de un conjunto mayor, la nación, resignando la posibilidad de que esa diferencia se constituyera en radical y capaz de disputar los patrones civilizatorios de la modernidad-colonialidad.

- En la relación entre los misioneros salesianos y los shuar, emergieron epistemologías y metodologías del encuentro relacionadas con la territorialización del otro a partir de la emergencia de lo inestable e inesperado y la ruptura de la linealidad y, sobre todo, un patrón epistémico territorial que incluye al otro en el propio ciclo vital colectivo, un aspecto impensable para la modernidad-colonialidad que se basa en la negación de esa posibilidad.

- He visto emerger una epistemología shuar afincada en los valores vitales, la corporalidad y en el pensar con el corazón. Desde allí aflora la conciencia del rasgo fundante de la pedagogía misionera: la repetición y la memorización no significativa frente al cultivo de la autonomía colectiva y del individuo en el territorio.

- Se evidenció la presencia de la espiritualidad de Arutam que alimenta una pedagogía y epistemología shuar decolonial, que articula lo que la modernidad-colonialidad escinde en relación con el cuerpo, la naturaleza y la espiritualidad.

Aquello que pervivió y busca renacer, la espiritualidad de Arutam, plantea disputas de fondo a los patrones civilizatorios de la modernidad-colonialidad, enunciados de la siguiente manera:

- La evangelización transportó el patrón civilizatorio de la desespiritualización de la naturaleza que condujo a diversas apropiaciones que van desde considerar el territorio shuar objeto de la razón instrumental y vacío de sentidos hasta constituirlo en objeto de colonización previa pacificación de los shuar. La corpoterritorialidad shuar disputa esos sentidos y prácticas desde su concepción del territorio vivido desde un nosotros, ii nunke, prehabitado por conocimientos, sentidos, 
fuerzas y seres diversos. Ii nunke es un espacio de coexistencia de presencias que deben vivir.

- Respecto a la espiritualidad, la evangelización y la educación formal transportaron el patrón civilizatorio de la escisión alma-cuerpo, introduciendo la abnegación como norma de subjetividad. La espiritualidad de Arutam, en cambio, diputa tal escisión mediante una práctica colectiva que integra la persona y valora la materialidad entendida como apego a los valores vitales y a las condiciones materiales de la existencia, al mismo tiempo que se afinca en la intensidad vital, en contra de la abnegación.

- La educación territorializó el patrón epistémico basado en el pensamiento dualista, según el cual la emoción y el sentimiento obnubilan la razón. Frente a este patrón civilizatorio, la pedagogía de Arutam propone un pensamiento corporizado, basado en el conocer desde la experiencia intransferible del sujeto, en el pensamiento concreto (contextual y situado), alerta a "lo que está por ocurrir".

\section{Aporte y preguntas pendientes}

Corresponde identificar los aportes distintivos de esta investigación, primero respecto a otras investigaciones sobre la misión shuar, luego, respecto a la opción del giro decolonial de los estudios (inter) culturales, para calibrar tanto aquello que se ha cubierto como lo que ha quedado pendiente.

Inicio diciendo que la misión salesiana ha estado presente en no pocos estudios referidos no tanto a ella misma como objeto de investigación, sino con relación al pueblo shuar, en especial sobre su proceso organizativo, donde los salesianos aparecen como actores que son tomados en cuenta por sus aportes a las condiciones materiales que hicieron posible la organización. La primera constancia de este tipo de investigación arranca con Münzel (1981), en que señala el aporte salesiano como impulsor de la misión pero, al mismo tiempo, destaca un proceso reconocido por otros autores que consiste en la progresiva autonomía 
respecto a los shuar, que no excluye el conflicto creciente con los misioneros, pues

En 1964, un misionero católico y shuar educados, fundaron la Federación Provincial de Centros Shuar de Morona-Santiago, al comienzo se trataba principalmente de una unión de seglares católicos con el fin de apoyar la misión salesiana, de un intento de afirmar en la población un catolicismo activo, lo que hasta entonces hacían principalmente los misioneros solos. Pero desde el comienzo se sumaron fines políticos a los religiosos. A lo largo de los años se desarrolló la Federación como delegación de los intereses de los indígenas, independiente de la misión y hasta en conflicto con ella. (236)

A esta primera y certera aproximación, refrendada por la historia, se suman algunos estudios como el de Salazar (1989) y Rubenstein (2005), cuyo objeto no es la misión, sino la organización que, de la misma manera, incluyen a los salesianos desde esa perspectiva. No obstante, quisiera abordar el aporte de la investigación a partir de otra perspectiva relacionada con mi lugar de enunciación. Yo no puedo mirar las cosas desde afuera porque, si bien no pertenezco ya jurídicamente a la comunidad salesiana, estoy ligado a ella sin poder desentenderme de sus fines y objetivos, aunque ello no signifique poder reinterpretarlos y enriquecerlos. Esta pertenencia obliga a ubicar estudios reflexivos desde dentro de la misma misión y, por ello, quisiera comentar muy brevemente el de Juan Bottasso (1982), el misionero que produjo el primer estudio crítico, desde dentro, sobre la misión salesiana no desde una perspectiva teológica, sino antropológica e historiográfica crítica. Yo admiro ese estudio y lo tuve siempre a mi lado a lo largo de mi escritura y reflexión, pero sentí que la opción por el proyecto de los estudios interculturales latinoamericanos debía procurar otra mirada.

A la vez que rescata los esfuerzos históricos de los misioneros que han intentado mirar de otra manera su presencia entre los shuar y que han visto cosas diferentes más allá de lo acostumbrado en la "empresa misionera", considero que la perspectiva de Bottasso es el primer cuestionamiento crítico del rol de los misioneros salesianos en Ecuador respecto a las tres dimensiones que articulan esta tesis: la civilización, la evangeli- 
zación y la educación. Definitivamente, desaprueba el rol civilizatorio de la misión porque implica el desconocimiento, la destrucción de los shuar y la negación de sus formas de vida y cultura (96 y s.), pero sobre todo porque implica la pérdida de su autonomía como pueblo (117 y s.). Respecto a la evangelización, rechaza la modalidad aculturante que implica la destrucción de su mundo simbólico y ritualidades (118 y s.). Asimismo, denuncia el proyecto educativo de los internados por viabilizar la aculturación, y la separación violenta y dolorosa de la niñez de sus hogares y de los ritmos comunitarios, una práctica indefendible entonces y ahora.

El eje de su crítica es disciplinar y se funda en la antropología porque "seculariza la visión de las culturas [frente a la unicidad cultural que acompaña la mentalidad misionera], porque a sus ojos todas las culturas [y todas las religiones] son igualmente legítimas: ella las analiza, pero no las juzga" $(1982,7)$. Asimismo, es significativa su articulación del conocer-poder que hace conciencia del etnocentrismo misionero (53 y s.) que puede ser cambiado desde el conocimiento cultural. Al tener en mente a los misioneros como lectores primarios, al tomar como punto de partida el concepto de cultura y el poder aculturizante de la misión, busca modelar una actitud abierta y respetuosa respecto a la diferencia étnica que contribuye a cambiar sus prácticas, pero para ello es menester acercarse a las culturas desde la antropología y sus posibilidades.

Leído su punto de partida desde la opción decolonial de los estudios (inter)culturales (Walsh 2009b) que orienta el rumbo de la investigación, puedo afirmar que su enfoque deja flotando en el aire la posibilidad de que la misión pueda autoadjudicarse una tarea civilizadora, evangelizadora y educadora, respetuosa y atenta a la diversidad, pero sin tocar el punto crucial de la misionalidad condicionada, en lo profundo y de todas maneras, por la universalidad y la totalidad. Queda flotando que, sin esas dimensiones (civilización, evangelización y educación), los pueblos indígenas resultan incompletos por carecer de ellas o no ajustarse del todo a lo que cabe esperar.

Puedo decir que esta perspectiva se afinca en la multiculturalidad que reconoce y favorece la diferencia y la equidad entre las culturas pero que, al mismo tiempo, tiende a desconocer no solo las relaciones de po- 
der entre las culturas sino también la incompatibilidad y la criticidad radical de algunas culturas — la de los pueblos indígenas - respecto a los patrones civilizatorios y la forma neoliberal del capitalismo global concebido como único presente posible. Esto es cierto también para la misión porque el espacio que concede a las culturas es funcional, sin asumirlas en su potencial de cuestionarse radicalmente. Las culturas indígenas serán siempre valoradas respecto a los fines misioneros, sin nada o poco que decir a las misiones, sin capacidad de cuestionar ningún tipo de patrón civilizatorio que ellas transportan, expresado en la espiritualidad y en las prácticas pedagógicas más allá de sí misma, porque los caminos estarán siempre bloqueados.

Esta investigación me ha enseñado que los shuar se las pudieron arreglar con los misioneros, así como con otros actores, pero los misioneros no saben/mos qué hacer con lo que ellos nos muestran; el punto crucial que cabe preguntarse se dirige a nosotros mismos: qué hacer con nuestras pertenencias a partir de las diferencias radicales; qué nos denuncian; qué caminos nos señalan para nosotros. Yo he sentido que la Iglesia y los misioneros, así como muchos pedagogos no indígenas, buscan siempre respetar la diferencia pero nunca cuestionarse qué significa esa diferencia para sí mismos, para su proyecto y en qué los confronta.

La investigación no ha buscado deslegitimar los aportes de Juan Bottasso ni mucho menos; tan solo especificar el cambio de perspectiva y la diferencia que conlleva partir de la cultura o de la civilización. En efecto, la perspectiva decolonial no puede asumir que es posible y viable sentirse autorizado para hacer algo para y en lugar de los otros, tal como la actitud misional tiende a realizar de una $\mathrm{u}$ otra manera. Además, la misionalidad que late en el fondo construye permanentemente dispositivos de negación destinados a eludir la oportunidad contenida en los pensamientos subalternizados y exteriorizados. De ese modo, la misión se absuelve a sí misma de la posibilidad ofrecida, se priva de ella, porque esos conocimientos otros, esas cosmovisiones otras, son parte también de su propio ciclo vital, una posible salida de la inhumanidad que comporta la colonialidad misional. Como hemos visto, la parodia sobre el pensamiento materialista shuar — revisada en el segundo ca- 
pítulo y retomada aquí- es un buen ejemplo de conciencia misional reprimida en sí misma que refuta la posibilidad ofrecida de pensarse y ser de otro modo, la posibilidad de habitar otra territorialidad epistémica. La actitud misional se niega a sí misma la posibilidad de ser parte de un proyecto decolonial fanoniano que busca "dislocar al mundo colonial" y "destruir el mundo colonial", precisamente porque su mirada está volcada hacia el otro en tanto objeto: "[D]islocar al mundo colonial no significa que después de la abolición de las fronteras se arreglará la comunicación entre las dos zonas. Destruir el mundo colonial es, ni más ni menos, abolir una zona, enterrarla en lo más profundo de la tierra o expulsarla del territorio" (Fanon [1961] 1983, 20).

Culmino con los siguientes interrogantes abiertos y pendientes para futuras indagaciones y trayectorias. Esos interrogantes se refieren a nosotros, entendidos como aquellos sujetos no shuar, pertenecientes a instancias e instituciones educativas ocasionalmente requeridas por los shuar, para recoger el desafío decolonizador de su experiencia histórica:

- ¿De qué manera las prácticas de educación shuar (sus métodos, sus epistemologías) pueden contribuir a decolonizar la educación formal, en todos sus niveles?

- ¿Cuáles aspectos de su vida en el territorio (ii nunke) disputan los patrones civilizatorios de la razón instrumental sobre la naturaleza?

- ¿Cómo asumir sus formas de vida para trascender el patrón de economía política que alienta el extractivismo y el consumo?

- ¿De qué manera la conversación (aujmatsamu) puede ser enriquecida como método para decolonizar la investigación conjunta en función de disputar los patrones civilizatorios de la modernidad-colonialidad?

- ¿Cómo decolonizar el cristianismo para transformarlo de una empresa misional a una espiritualidad basada en la intensidad vital y el compromiso por la vida expandida de los colectivos subalternizados? 